\title{
Inhibitory Effect of Electrolyzed Reduced Water on Tumor Angiogenesis
}

\author{
Jun Ye ${ }^{a, b}$ Yuping LI, ${ }^{a, c}$ Takeki HamasaKi, ${ }^{d}$ Noboru NAKAmichi, ${ }^{e}$ Takaaki Komatsu, ${ }^{d}$ \\ Taichi Kashiwagi, ${ }^{d}$ Kiichiro Teruya, ${ }^{a, d}$ Ryuhei Nishikawa, ${ }^{d}$ Takeshi Kawahara, ${ }^{d}$ Kazuhiro OsadA, ${ }^{d}$ \\ Kazuko Toh, ${ }^{d}$ Masumi Abe ${ }^{d}$ Huaize Tian, ${ }^{d}$ Shigeru Kabayama, ${ }^{f}$ Kazumichi Otsubo, ${ }^{f}$ \\ Shinkatsu Morisawa, ${ }^{f}$ Yoshinori Katakura, ${ }^{a, d}$ and Sanetaka Shirahata ${ }^{*, a, d}$ \\ ${ }^{a}$ Graduate School of Systems Life Sciences, Kyushu University; ${ }^{d}$ Department of Genetic Resources Technology, Faculty of \\ Agriculture, Kyushu University; 6-10-1 Hakozaki, Higashi-ku, Fukuoka 812-8581, Japan: ${ }^{b}$ Key Laboratory of the \\ Ministry of Education for Cell Biology and Tumor Cell Engineering, School of Life Science, Xiamen University; Fujian, \\ 361005 P.R. China: ${ }^{c}$ School of Life Sciences, Nanchang University of Science and Technology; Nanchang 330006, P.R. \\ China: ${ }^{e}$ Functional Water Cell Analysis Center Co., Ltd.; Fukuoka 812-0053, Japan: and ${ }^{f}$ Nihon Trim Co., Ltd.; 1-8-34 \\ Oyodonaka, Kita-ku, Osaka 531-0076, Japan.
}

Received June 9, 2007; accepted October 16, 2007; published online October 17, 2007

Vascular endothelial growth factor (VEGF) is a key mediator of tumor angiogenesis. Tumor cells are exposed to higher oxidative stress compared to normal cells. Numerous reports have demonstrated that the intracellular redox (oxidation/reduction) state is closely associated with the pattern of VEGF expression. Electrolyzed reduced water (ERW) produced near the cathode during the electrolysis of water scavenged intracellular $\mathrm{H}_{2} \mathrm{O}_{2}$ and decreased the release of $\mathrm{H}_{2} \mathrm{O}_{2}$ from a human lung adenocarcinoma cell line, A549, and down-regulated both VEGF transcription and protein secretion in a time-dependent manner. To investigate the signal transduction pathway involved in regulating VEGF expression, mitogen-activated kinase (MAPK) specific inhibitors, SB203580 (p38 MAPK inhibitor), PD98059 (ERK1/2 inhibitor) and JNKi (c-Jun N-terminal protein kinase inhibitor) were applied. The results showed that only PD98059 blocks VEGF expression, suggesting an important role for ERK1/2 in regulating VEGF expression in A549 cells. As well, ERW inhibited the activation of extracellular signal-regulated kinase (ERK) in a time-dependent manner. Co-culture experiments to analyze in vitro tubule formation assay revealed that A549 cell-derived conditioned medium significantly stimulated the formation of vascular tubules in all analyzed parameters; tubule total area, tubule junction, number of tubules, and total tubule length. ERW counteracted the effect of A549 cell-conditioned medium and decreased total tube length $(p<0.01)$. The present study demonstrated that ERW down-regulated VEGF gene transcription and protein secretion through inactivation of ERK.

Key words electrolyzed reduced water; angiogenesis; oxidative stress; vascular endothelial growth factor; extracellular signalregulated kinase; A549 cell-conditioned medium

Tumor angiogenesis, the formation of new blood capillaries by vascular endothelial cells from existing vessels, is an important mechanism for supplying nutrients, oxygen, growth factors and others to tumor cells. Tumor cells trigger angiogenesis by secreting angiogenic factors, especially vascular endothelial growth factor (VEGF-A) ${ }^{1}{ }^{1}$ which plays an important role in the regulation of normal and abnormal angiogenesis. $^{2)}$

VEGF-A (commonly known as VEGF) was first reported as a vascular permeability-inducing factor secreted by tumor cells, and referred to as vascular permeability factor (VPF). ${ }^{3)}$ VEGF gene expression is initiated by extracellular signals including growth factors, mitogens, phorbol ester, cytokines and extracellular stresses. The first three of these exogenous signals activate the Ras-Raf-MEK-ERK pathway that transduces mitogenic signals regulating cell proliferation or differentiation. The other extracellular signals activate the JNK/SAPK and p38 pathways that regulate cellular inflammatory or stress responses. ${ }^{4)}$ VEGF is overexpressed at both mRNA and protein levels in a high percentage of malignant animal and human tumors, as well as in many immortalized and transformed cell lines. ${ }^{5-7)}$ The VEGF-A gene transcript undergoes alternative splicing to yield mature isoforms of $121,165,189$, and 206 amino acids, with $\mathrm{VEGF}_{165}$ appearing to be quantitatively and functionally predominant in most angiogenic states. ${ }^{8)} \mathrm{VEGF}_{121}$ and $\mathrm{VEGF}_{165}$ are secreted as solu- ble compounds, whereas $\mathrm{VEGF}_{189}$ and $\mathrm{VEGF}_{206}$ remain cell surface associated or are primarily deposited in the extracellular matrix. ${ }^{9)}$

Reactive oxygen species (ROS) are suggested to play an important role in angiogenesis. ${ }^{10)}$ Furthermore, there is increasing evidence of the involvement of $\mathrm{H}_{2} \mathrm{O}_{2}$ in the regulation of angiogenesis. ${ }^{9,11-13)}$ As well, a variety of cell lines derived from human tumors has been shown to produce large amounts of $\mathrm{H}_{2} \mathrm{O}_{2} \cdot{ }^{14)}$ Constitutive surveillance for cellular protection against oxidative stress is conferred by intracellular antioxidative agents. ${ }^{15)}$ Excess amounts of ROS are toxic and cause a reduction of intracellular antioxidant levels. ${ }^{16)}$ It has been reported that pretreatment of the heart with exogenous antioxidants improved its condition as a result of reducing ROS production. ${ }^{17)}$ The VEGF-A gene is one that has its expression regulated by ROS, especially by $\mathrm{H}_{2} \mathrm{O}_{2}$. Additional data support that VEGF-A mRNA is up-regulated by $\mathrm{H}_{2} \mathrm{O}_{2}$ in a dose- and time-dependent manner. ${ }^{18,19)}$ Taken together, these suggest that some endogenous as well as exogenous antioxidative agents can be used to regulate VEGF-A gene expression and/or $\mathrm{H}_{2} \mathrm{O}_{2}$ production for therapeutic purposes.

Electrolyzed reduced water (ERW) has attracted much attention because of its antioxidative potential. Water electrolysis typically produces two forms of water: reduced or alkaline (high $\mathrm{pH}$ ) water near the cathode and an oxidized or acid (low $\mathrm{pH}$ ) water near the anode. Applications of oxidized 
water have frequently been reported. ${ }^{20-22)}$ In Japan, ERW produced from tap water by house-use electrolyzing purifiers is popular as it is thought to have health benefits. ERW has been shown to be clinically effective in the treatment of patients with irritable bowel syndrome or non-ulcer dyspepsia. ${ }^{23)}$ Shirahata et al. first demonstrated that ERW not only exhibited high $\mathrm{pH}$, low dissolved oxygen, extremely high dissolved molecular hydrogen, but most importantly, showed ROS scavenging activity and protective effects against oxidative damage to DNA. ${ }^{24)}$ Thereafter, the inhibitory effects of ERW on alloxan-induced pancreatic cell damage ${ }^{25)}$ and on hemodialysis-induced oxidative stress in end-stage renal disease (ESRD) patients ${ }^{26,27)}$ were reported. Kim and Kim reported that ERW derived from tap water exhibited an antitype 2 diabetic effect in animal experiments. ${ }^{28)}$

Although the data accumulated so far suggest that ERW could be a useful antioxidative agent, further studies are required to elucidate the mechanisms of its actions in cells. To this end, we hypothesized that ERW could regulate VEGF-A gene expression to exert antiangiogenic effects via scavenging ROS, in particular $\mathrm{H}_{2} \mathrm{O}_{2}$. We carried out a series of experiments as a first step to uncover the mechanisms involved.

Here we present evidence that ERW attenuates both the release of $\mathrm{H}_{2} \mathrm{O}_{2}$ and the secretion of VEGF. This then leads to the suppression of angiogenesis induced by tumor cells.

\section{MATERIALS AND METHODS}

Preparation of Electrolyzed Reduced Water (ERW) ERW (oxidation reduction potential, $-600 \mathrm{mV}$; pH 11) was prepared by electrolyzing ultra pure water containing $0.002 \mathrm{M}$ $\mathrm{NaOH}$ at $100 \mathrm{~V}$ for $60 \mathrm{~min}$ using an electrolyzing device equipped with platinum-coated titanium electrodes (TI-200s, Nihon Trim Co., Osaka, Japan), and typically contains $0.2 \mathrm{ppb}$ Pt Nps when assayed with ICP-MS spectrometer (unpublished data). A batch type electrolyzing device was used. It consisted of a 4-1 vessel $(190 \mathrm{~mm}$ length $\times 210 \mathrm{~mm}$ width $\times$ $140 \mathrm{~mm}$ height) divided by a semi-permeable membrane ( $190 \mathrm{~mm}$ width $\times 130 \mathrm{~mm}$ height, $0.22 \mathrm{~mm}$ thickness, pore size is not disclosed, Yuasa Membrane System Co., Osaka Japan). Two electrodes ( $70 \mathrm{~mm}$ width $\times 110 \mathrm{~mm}$ length) were placed at a distance of $55 \mathrm{~mm}$ from each side of the semipermeable membrane.

Cell Culture and Reagents All electrolyzed alkaline ERW was neutralized by adding $1 \mathrm{ml}$ of $10 \times$ minimum Eagle's medium (MEM) ( $\mathrm{pH} \mathrm{7)}$ and $0.2 \mathrm{ml}$ of $1 \mathrm{~m} \mathrm{4-(2-hy-}$ droxyethyl)piperazine-1-ethanesulfonic acid (HEPES) buffer ( $\mathrm{pH} 5.3$ ) to $9 \mathrm{ml}$ of ERW ( $\mathrm{pH} \mathrm{11)} \mathrm{before} \mathrm{use.} \mathrm{Human} \mathrm{lung}$ adenocarcinoma, A549 cells and human diploid embryonic lung fibroblast, TIG-1 cells were obtained from the Health Science Research Resources Bank and maintained in MEM supplemented with $10 \%$ fetal bovine serum (FBS) designated as $10 \% \mathrm{FBS} / \mathrm{MEM}$ (Biowest, France). During the experiments, A549 cells were cultured with MEM (no FBS) prepared by dilution of $10 \times$ MEM with Milli $Q$ water which designated as serum-free MEM/Milli $Q$ or cultured with MEM (no FBS) prepared by dilution of $10 \times$ MEM with ERW which designated as serum-free MEM/ERW. In a preliminary experiment done in the past, we had compared two MEM media prepared either with $0.002 \mathrm{M} \mathrm{NaOH}$ aqueous solution or with Milli $Q$ water to examine whether MEM media with addition of $\mathrm{NaOH}$ could scavenge intracellular ROS or not, and such effect was not observed. Also, these MEM media were applied to human fibrosarcoma HT1080 cells and measured matrix metalloproteinase (MMP) gene expressions. We did not observe any difference in the levels of MMP expression between HT1080 cells cultured with the two MEM media (unpublished observation). Together with these observations and the knowledge that both MMP and VEGF are redox-sensitive genes, we judged that an addition of $\mathrm{NaOH}$ into culture media has no effect on intracellular redox state and related genes expression. We therefore used MEM media prepared with Milli Q water as a control in subsequent experiments.

Human umbilical vein endothelial cells (HUVEC) were purchased from Cambrex and cultured in EGM-2 medium (Cambrex, MD, U.S.A.). Homovanillic acid (HVA) and horseradish peroxidase type VI were purchased from Sigma Chemical Co. (St. Louis, MO, U.S.A.). SB203580, PD98059 and c-Jun N-terminal protein kinases inhibitor (JNKi) were purchased from Calbiochem (CA, U.S.A.). The Quantikine kit (Human VEGF Immunoassay, Catalog Number DVE00) was obtained from R\&D Systems, Inc. (Minneapolis, MN, U.S.A.). The Quantikine VEGF Immunoassay kit is designed to measure VEGF $_{165}$ levels in cell culture supernates. An Angiogenesis Tubule Staining Kit (for staining CD31) was obtained from TCS Cellworks (Buckingham, U.K.). Total and phospho-ERK mitogen-activated protein kinase (MAPK) antibody was purchased from Cell Signaling Technology (Danvers, MA, U.S.A.). 2',7'-Dichlorofluorescein diacetate (DCFH-DA) was purchased from Molecular Probes, Inc. (Eugene, OR, U.S.A.).

Measurement of Intracellular $\mathrm{H}_{2} \mathrm{O}_{2}$ Scavenging Activity by ERW $\mathrm{H}_{2} \mathrm{O}_{2}$ produced in A549 cells was measured using DCFH-DA. A549 cells were pretreated with serumfree MEM/ERW for $30 \mathrm{~min}$, and then incubated with $5 \mu \mathrm{M}$ DCFH-DA for $30 \mathrm{~min}$ at $37^{\circ} \mathrm{C}$. DCFH-DA diffused freely into cells and was then hydrolyzed by cellular esterases to DCFH, which was trapped within the cell. This non-fluorescent molecule was then oxidized to fluorescent dichlorofluorescein (DCF) by the action of intracellular $\mathrm{H}_{2} \mathrm{O}_{2}$. Cells were washed with phosphate-buffered saline (PBS, $\mathrm{pH}$ 7.4) to remove the DCFH-DA. $\mathrm{H}_{2} \mathrm{O}_{2}$ levels were measured using flow cytometry (EPICS XL System II; Beckman Coulter, U.S.A.) by determining the intensity of the fluorescence relative to that of control cells.

Measurement of $\mathrm{H}_{2} \mathrm{O}_{2}$ Release $\mathrm{H}_{2} \mathrm{O}_{2}$ release from A549 cells into the culture medium was assayed by a published method. ${ }^{29)}$ Briefly, A549 cells were cultured in a 24well plate with serum-free MEM/Milli Q or serum-free $\mathrm{MEM} / \mathrm{ERW}$ for $24 \mathrm{~h}$. The cells were washed with PBS and then incubated with an $800 \mu \mathrm{l}$ reaction buffer $(100 \mu \mathrm{M}$ HVA, 5 units/ml horseradish peroxidase type VI, and $1 \mathrm{mM}$ HEPES in Hanks balanced salt solution without phenol red, $\mathrm{pH}$ 7.4). The reaction buffer without cells was treated in the same way, as a control. This solution was then collected after incubation for $30 \mathrm{~min}, \mathrm{pH}$ was adjusted to 10.0 with $0.1 \mathrm{M}$ glycine- $\mathrm{NaOH}$ buffer, and fluorescence was then measured using a fluorescence spectrophotometer (F-2500, Hitachi, Japan) at excitation and emission wavelengths of $321 \mathrm{~nm}$ and $421 \mathrm{~nm}$, respectively.

Semiquantitative Reverse Transcription-Polymerase 
Chain Reaction (RT-PCR) Total RNA was isolated using a GenElute ${ }^{\mathrm{TM}}$ Mammalian Total RNA isolation kit (Sigma Chemical Co., St. Louis, MO, U.S.A.) and following the protocol provided by the supplier. The primer sequences for glyceraldehyde-3'-phosphate dehydrogenase (GAPDH) are 5'ACCACAGTCCATGCCATCAC3' (forward) and 5'TCCACCACCCTGTTGCTGTA-3' (reverse), which amplify a 512 bp segment (NCBI Acc\#: NM 002046). The common primer sequences for VEGF transcripts are 5'GGGCCTCCGAAACCATGAAC3' (forward) and 5'CTGGTTCCCGAAACCCTGAG3' (reverse), which differentiate alternatively spliced $\mathrm{VEGF}_{165}$ and $\mathrm{VEGF}_{121}$ transcripts by generating $625 \mathrm{bp}$ and $495 \mathrm{bp}$ fragments, respectively. ${ }^{8,30)}$ PCR amplification for VEGF was carried out at $94{ }^{\circ} \mathrm{C}$ for $45 \mathrm{~s}$ of denaturing, annealing for $45 \mathrm{~s}$ at $60^{\circ} \mathrm{C}$, and extension for $1 \mathrm{~min}$ at $72^{\circ} \mathrm{C}$ for 35 cycles using Taq polymerase (Takara). Likewise, PCR amplification for GAPDH was carried out at $94^{\circ} \mathrm{C}$ for $3.5 \mathrm{~min}$ of denaturing, annealing for $30 \mathrm{~s}$ at $58^{\circ} \mathrm{C}$, and extension for $1 \mathrm{~min}$ at $72^{\circ} \mathrm{C}$ for 30 cycles. The semi-quantitative RT-PCR products were not saturated under the conditions used in the present experiments. Amplified products were resolved by agarose gel electrophoresis and then photographed with a digital camera (ATTO, Tokyo). For densitometric analysis, recorded images were analyzed by an NIH image analyzer program (Image 1.62f) using a personal computer. Values below the panel were normalized by arbitrarily setting the density of the $\mathrm{VEGF}_{165}$ and $\mathrm{VEGF}_{121}$ bands of untreated A549 cells to 1.0. GAPDH transcripts were used as an internal control for cellular activity.

Measurement of VEGF Secreted into the Culture Medium A549 cells $\left(5 \times 10^{4}\right.$ cells/well $)$ were seeded in 24 well plates with $10 \% \mathrm{FBS} / \mathrm{MEM}$ and cultured overnight. The medium was replaced with serum-free MEM/ERW and incubated for another $24 \mathrm{~h}$. The conditioned medium was collected to measure secreted VEGF, which was measured according to the manufacturer's protocol.

Preparation of Conditioned Medium and Tubule Formation Assay A549 cells $\left(1 \times 10^{6}\right.$ cells $)$ were seeded in a $90 \mathrm{~mm}$ dish with $10 \% \mathrm{FBS} / \mathrm{MEM}$ and incubated overnight. The medium was replaced with serum-free MEM/Milli Q or serum-free MEM/ERW and cultured for $24 \mathrm{~h}$. The conditioned medium was collected and filtered with a $0.2 \mu \mathrm{m}$ filter. Aliquots were stored in a $-80^{\circ} \mathrm{C}$ deep-freezer. Tubule formation assay was performed with a co-culture system. HUVEC were mixed with TIG-1 cells at $1: 40$, seeded in 24well plates, and cultured in EGM-2 medium overnight. The medium was removed and a mixture of A549 cell conditioned and EGM-2 media mixed at $2: 1$ was added. The conditioned medium was changed every $2 \mathrm{~d}$. Tubules formed with different media were detected with HUVEC-specific markers CD31 (PECAM-1). Briefly, at day 11, the medium was completely removed, and the co-culture plate was fixed for $30 \mathrm{~min}$ with $70 \%$ ethanol solution. After incubation with PBS containing $1 \%$ bovine serum albumin (BSA), the coculture plate was incubated with a mouse anti-human CD31 antibody $(1: 4000)$ for $60 \mathrm{~min}$, followed by another $60 \mathrm{~min}$ incubation with a secondary goat anti-mouse IgG antibody conjugated with alkaline phosphatase (both antibodies were included in the Tubule Staining Kit). After washing the culture plate, 5-bromo-4-chloro-3-indolylphosphate toluidine salt/nitro-blue tetrazolium chloride (BCIP/NBT) substrate was added until tubules developed a dark purple color. Cocultures were then dried and analyzed. Tubule formations in the co-culture system were observed by phase-contrast microscopy and photomicrographs were documented with a digital camera (Olympus, Japan). Recorded images were analyzed by Angiogenesis Image Analysis Software (AngioSys 1.0, TCS, Cellworks, U.K.). Twelve random fields per well were photographed for tubule formation assessment.

Western Blot Analysis Appropriately treated cells were washed with PBS, and incubated with extraction buffer (50 mm Tris- $\mathrm{HCl}$ pH 7.5, $150 \mathrm{~mm} \mathrm{NaCl,} 1 \mathrm{~mm}$ PMSF, 1\% NP-40, $0.1 \%$ SDS, $10 \mu \mathrm{g} / \mathrm{ml}$ aprotinin and $10 \mathrm{~mm}$ EDTA) on ice. Cells were collected with a scraper. The lysate was then centrifuged at $12000 \times \boldsymbol{g}$ for $5 \mathrm{~min}$. Thirty micrograms of protein samples were boiled in a ratio of $3: 1$ with sample buffer (250 mm Tris- $\mathrm{HCl} \mathrm{pH} 6.8,40 \%$ glycerol, $20 \% \beta$-mercaptoethanol, $8 \%$ SDS and $0.04 \%$ bromophenol blue), and electrophoresed in SDS-PAGE. Resolved proteins were then transferred onto Hybond-ECL membranes (Amersham Bioscience, U.K.), which were blocked with $0.05 \%$ Tween 20 PBS (T-PBS) containing 10\% skim milk powder (Wako, Osaka, Japan) and probed with primary and secondary antibodies coupled with peroxidase. After washing three times with T-PBS, the bound antibody was developed using an ECL plus Western Blotting Detection System (Amersham Biosciences, U.K.).

\section{RESULTS}

ERW Scavenges Intracellular $\mathrm{H}_{2} \mathrm{O}_{2}$ and Decreases the Release of $\mathrm{H}_{2} \mathrm{O}_{2}$ from $\mathrm{A549}$ Cells It has been reported that cancer cells produce high amounts of ROS, including $\mathrm{H}_{2} \mathrm{O}_{2},{ }^{14)}$ and that exogenous ROS stimulates induction of VEGF in various cell types. ${ }^{18,31)}$ ERW has been shown to effectively scavenge intracellular ROS in HIT-T15 cells (a hamster pancreatic cell line). ${ }^{25)}$ These data together suggest that ERW might regulate VEGF expression by way of ROS. To test this idea and to ascertain if the ROS scavenging activity of ERW is applicable to other cell types, we began by examining the scavenging effect of ERW in A549 cells. A549 cells were treated with MEM containing ERW and then incubated with DCFH-DA. Intracellular $\mathrm{H}_{2} \mathrm{O}_{2}$ levels were measured using flow cytometry by determining the intensity of the fluorescence relative to that of control cells, as detailed in the Materials and Methods. The results showed a reduction of intracellular $\mathrm{H}_{2} \mathrm{O}_{2}$, as the signal curve obtained from ERWtreated A549 cells (designated as "ERW") was shifted to the left compared with untreated A549 cells (designated as "Control") (Fig. 1A). This shift of the signal curve would indicate scavenging of $\mathrm{H}_{2} \mathrm{O}_{2}$. Thus ERW was suggested to scavenge intracellular $\mathrm{H}_{2} \mathrm{O}_{2}$ in A549 cells. To test the ROS scavenging activity of ERW, we examined the effect of ERW on the release of $\mathrm{H}_{2} \mathrm{O}_{2}$ from A549 cells. Our test method was based on the conversion of homovanillic acid, a substituted phenol, to its fluorescent dimer in the presence of $\mathrm{H}_{2} \mathrm{O}_{2}$ and horseradish peroxidase. As shown in Fig. 1B, when A549 cells were pre-treated with ERW for $24 \mathrm{~h}$, the release of $\mathrm{H}_{2} \mathrm{O}_{2}$ from A549 cells decreased to approximately 40\% compared to non-treated control $(p<0.05)$. Thus, the results confirmed a previous report. ${ }^{25)}$

The present results from two different assays capable of 
A
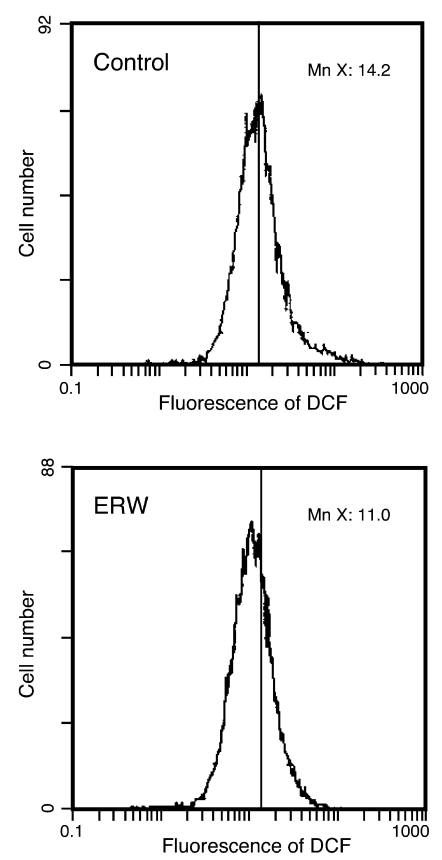

B

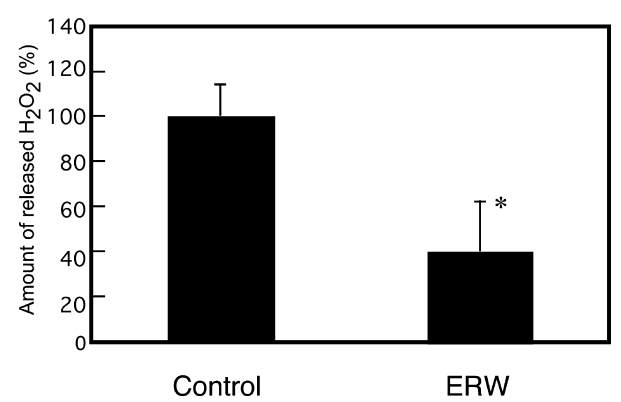

Fig. 1. Intracellular $\mathrm{H}_{2} \mathrm{O}_{2}$ Scavenging Activity of ERW (A) and Suppression of $\mathrm{H}_{2} \mathrm{O}_{2}$ Release from A549 Cells by ERW (B)

(A) Cultured A549 cells were pretreated for $30 \mathrm{~min}$ with $10 \% \mathrm{FBS} / \mathrm{MEM} / \mathrm{ERW}$, then incubated with $5 \mu \mathrm{M}$ DCFH-DA for $30 \mathrm{~min}$ at $37^{\circ} \mathrm{C}$. The fluorescence intensity of $\mathrm{DCFH}$ was measured with a flow cytometer. The fluorescence intensity relative to that of control cells is presented as curves. The curve designated as "Control" is the fluorescence intensity obtained from control A549 cells. The curve designated as "ERW" is the fluorescence intensity obtained from A549 cells treated with ERW. $\mathrm{H}_{2} \mathrm{O}_{2}$ scavenging activity was judged positive, as the ERW-treatment curve (ERW) was shifted to the left compared with the control curve (Control). Mn X in the ERW and Control panels means the mean of fluorescence intensity. A representative result is shown from three independent experiments. (B) ERW was added to A549 cells in culture followed by further $24 \mathrm{~h}$ incubation. Released $\mathrm{H}_{2} \mathrm{O}_{2}$ in the culture media was measured as described in Materials and Methods. Differences were analyzed by Student's $t$ test (values are the mean \pm S.D., $n=3$ ). An asterisk represents a significant difference compared with controls $(* p<0.05)$ and $p$ values of $<0.05$ are considered statistically significant.

measuring endogenous and exogenous $\mathrm{H}_{2} \mathrm{O}_{2}$ levels clearly demonstrated that ERW has the potential to reduce and/or scavenge $\mathrm{H}_{2} \mathrm{O}_{2}$.

ERW Inhibits Both VEGF Gene Expression and Extracellular Secretion in A549 Cells As we had confirmed that ERW reduces $\mathrm{H}_{2} \mathrm{O}_{2}$ production from A549 cells, we investigated using an RT-PCR method to determine if $\mathrm{H}_{2} \mathrm{O}_{2}$ and VEGF levels are coordinately regulated by ERW in A549 cells.

Primers were designed to amplify a 495 bp product for the $\mathrm{VEGF}_{121}$ transcript and a $625 \mathrm{bp}$ product for the $\mathrm{VEGF}_{165}$ transcript. Agarose gel electrophoresis was performed to dis-
A

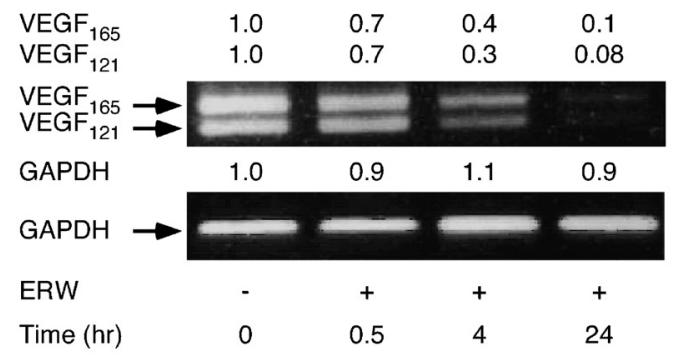

B

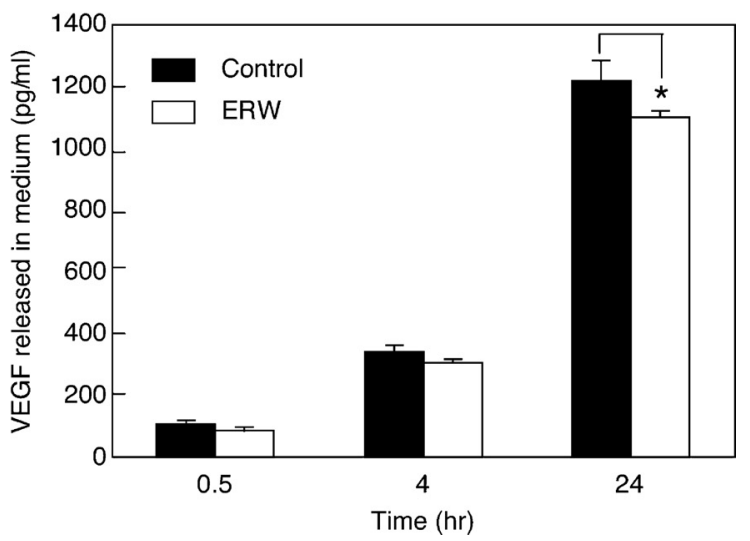

Fig. 2. ERW Down-Regulates VEGF Transcription and Secretion

(A) Four sets of A549 cells were treated with ERW for 0.5, 4 and $24 \mathrm{~h}$. A549 cells treated for designated time periods were used to isolate total RNAs. VEGF and GAPDH transcripts were detected by RT-PCR with an appropriate set of primers, as shown in Materials and Methods. Values above the panel were normalized by arbitrarily setting the densitometry of VEGF ${ }_{165}$ and $\mathrm{VEGF}_{121}$ bands at time zero to 1.0. A GAPDH transcript was used as an internal control for cellular activity. (B) A549 $\left(5 \times 10^{5}\right.$ cells $)$ cells/well were seeded in 24-well plates with $10 \%$ FBS/MEM for $0.5,4$ and $24 \mathrm{~h}$. The medium was replaced with serum-free MEM/ERW for the indicated time periods. The medium was collected to measure an amount of VEGF secreted by A549 cells, as described in Materials and Methods. Filled columns $(\mathbf{\square})$, controls cultured in serum-free MEM/Milli Q; open columns ( $\square$ ), tests cultured in serum-free MEM/ERW. The results of 3 independent experiments were analyzed by Student's $t$ test (values are the mean \pm S.D., $n=3)$. An asterisk represents a significant difference compared with the control $(* p<0.05)$ and $p$ values of $<0.05$ are considered statistically significant.

solve RT-PCR products (Fig. 2A). Ratios of band intensities between different incubation periods for GAPDH and those for the two VEGF isoform products were used to compare time dependent transcription levels (Fig. 2). The results showed that ERW treatment down-regulated transcriptions of VEGF $_{165}$ and $\mathrm{VEGF}_{121}$ in a time-dependent manner. Notably, when the cells were treated with ERW for $24 \mathrm{~h}$, VEGF transcription was significantly suppressed, while that of GAPDH changed little; indicating that the results were not due to the cytotoxic effects of ERW (Fig. 2A).

VEGF is known to be secreted outside tumor cells to exert its angiogenic effect by stimulating proliferation and migration of endothelial cells. ${ }^{18)}$ Therefore, the effect of ERW on the secretion of VEGF in A549 cells was tested. The secretion of VEGF from control cells increased in a time-dependent manner, whereas ERW gradually suppressed the increase in the VEGF secretion (Fig. 2B). A significant difference in the secreted VEGF accumulations between control $(1217.94 \pm 61.83 \mathrm{pg} / \mathrm{ml})$ and treated samples (1095.53士 $21.50 \mathrm{pg} / \mathrm{ml}$ ) was only observed when A549 cells were 
treated with ERW for $24 \mathrm{~h}(p<0.05$, Fig. 2B). This delayed response of VEGF protein secretion compared to VEGF gene transcription level, which after $4 \mathrm{~h}$ treatment reduced to approximately $30-40 \%$, may be attributable to assay point differences, i.e., transcription and accumulated protein levels because RT-PCR detects specific transcripts directly at specific time points while VEGF assay detects accumulated total VEGF $_{165}$ protein during the incubation periods indicated.

ERW Inactivates ERK1/2 VEGF gene transcription was demonstrated to be regulated by ERW, suggesting that its action point is at a gene transcription level and/or at signal transduction pathway levels upstream to transcription initiation complexes. As an initial step, the signal transduction pathway involved in regulating VEGF gene expression was investigated using MAPK specific inhibitors, SB203580 (p38 MAPK inhibitor), PD98059 (MEK inhibitor which is an upstream kinase of the ERK pathway) and JNKi (JNK inhibitor). For this purpose, the same RT-PCR assay system and analysis methods, as in Fig. 2A, were used to quantify VEGF transcripts (Fig. 3A). The results showed that only PD98059 blocked VEGF expression, suggesting an important role for the Ras-Raf-MEK-ERK pathway, particularly ERK1/2 factor, in regulating VEGF expression in A549 cells (Fig. 3A). Other inhibitors, SB203580 and JNKi, did not show any significant inhibitory effect on VEGF gene transcription, indicating that the $\mathrm{JNK} /$ stress activated protein $\mathrm{ki}$ nase (SAPK) and p38 pathways were not directly involved in

A

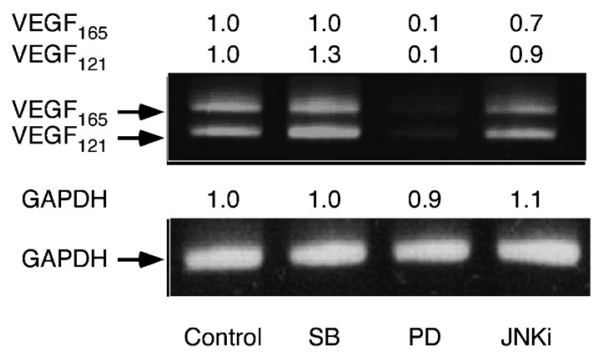

B

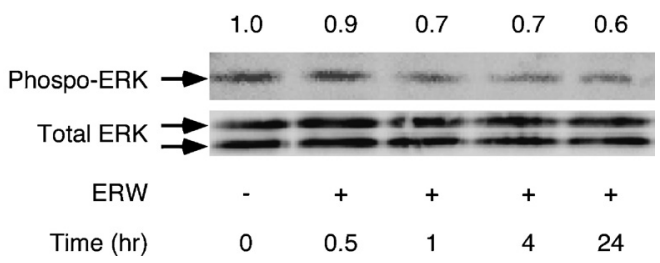

Fig. 3. VEGF Expression Is Down-Regulated via Inactivation of the ERK Pathway

(A) A549 cells were treated with serum-free MEM containing SB203580 $(10 \mu \mathrm{M})$ PD98059 $(20 \mu \mathrm{M})$ or JNK inhibitor II $(40 \mathrm{nM})$ for $24 \mathrm{~h}$ and total RNAs isolated. Total RNAs were used to amplify VEGF ${ }_{165}$ and VEGF VE $_{121}$ transcripts by RT-PCR with respective primer sets. Amplified products were resolved in an agarose gel electrophoresis and bands were photographed and documented using a digital camera. Recorded images were analyzed by an NIH image analyzer program (Image 1.62f) using a personal computer. Values above the panel were normalized by arbitrarily setting the densitometry of $\mathrm{VEGF}_{165}$ and $\mathrm{VEGF}_{12}$ bands at time zero to 1.0. A GAPDH transcript was used as an internal control for cellular activity. Control: no inhibitor, SB: SB203580 (p38 MAPK inhibitor), PD: PD98059 (MEK inhibitor), JNKi: JNK inhibitor. (B) A549 cells were incubated in serum-free MEM/ERW for the indicated time periods. Cell lysates were prepared and $30 \mu \mathrm{g}$ proteins from each lysate were resolved by SDS-PAGE and used for Western-blot analysis as described in Materials and Methods. Total- and phospho-ERK were detected using Total- and phospho-ERK MAPK antibodies. Values above the panel were normalized by arbitrarily setting the densitometry of phospho-ERK band to 1.0. Total ERK was used to monitor cellular activity.
VEGF gene transcription.

Further experiments were performed to determine whether ERW-induced down-regulation of VEGF expression is due to the suppression of ERK1/2 phosphorylation. Western blot analyses showed that phosphorylation of ERK decreased in a time-dependent manner from 0.5 to $4 \mathrm{~h}$. After $4 \mathrm{~h}$, the phospho-ERK level remained low for up to $24 \mathrm{~h}$, even after extended ERW treatment. The total amount of ERK MAPK protein was unaffected by ERW treatment (Fig. 3B). These results further strengthened the results shown in Fig. 3A. They also suggested that MEK is involved in the regulation of VEGF transcription via ERK phosphorylation.

Effect of ERW on Vascular Tubule Formation Induced by $\mathrm{A549}$ Cells Exogenous ROS is known to stimulate VEGF production ${ }^{18)}$ and to promote tubular morphogenesis in endothelial cells. ${ }^{32}$ ) To evaluate the effect of ERW on tubule formation, four parameters; tubule area, number of junctions, number of tubules, and total tube length, were measured. For this, a co-culture of HUVEC and TIG cells was incubated with mixtures of EGM-2 medium and nonconditioned MEM (Fig. 4A, Control), A549 conditioned MEM (Fig. 4B, A549 CM), and ERW-treated A549 conditioned MEM (Fig. 4C, ERW-A549 CM) at a ratio of $1: 2$, respectively. Co-cultures treated with the A549 conditioned MEM significantly increased the formation of vascular tubules in all analyzed parameters in comparison with control; that is, a $76 \%$ increase on total tubule areas, a $200 \%$ increase of the number of tubule junctions, a $179 \%$ increase of
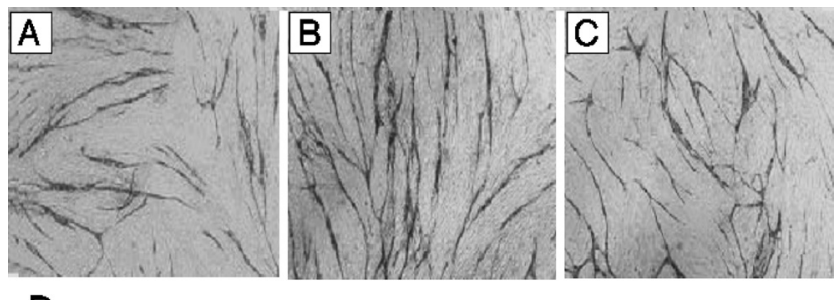

D

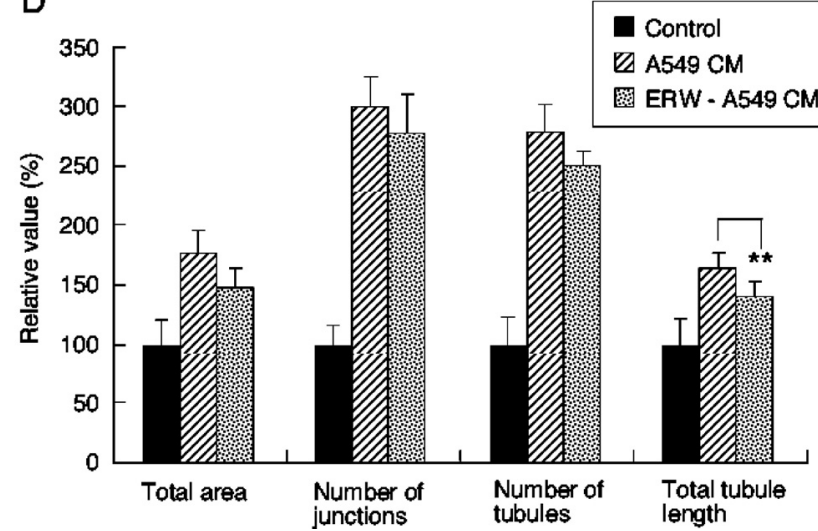

Fig. 4. Effects of ERW on A549 Cell Conditioned Medium-Induced Vascular Tubule Formation

HUVEC/TIG-1 co-culture in a 24-well plate was challenged with mixtures of EGM2 medium and non-conditioned MEM (A. Control), A549 cell conditioned MEM (B A549 CM) and ERW-treated A549 cell conditioned MEM (C. ERW-A549 CM) mixed at $1: 2$, respectively. Media were changed every $2 \mathrm{~d}$. At day 11 , tubule formations were detected with a Tubule Staining Kit and visualized by phase-contrast microscopy. Photomicrographs from a digital camera were used to characterize tubules. Recorded images were analyzed by angiogenesis quantification software (D). Twelve random fields per well were pictured for tubule formation assessment. Data are expressed as a percentage of the total area, the number of junctions, the number of tubules and the tota tube length in untreated control cells (mean \pm S.E.). Asterisks represent a significant difference compared with controls $(* * p<0.01)$. $p$ values of $<0.05$ were considered statistically significant 
the number of tubules, and a $65 \%$ increase of total tubule length, respectively (Fig. 4D: compares control and A549 $\mathrm{CM})$. Taking these results into consideration, conditioned medium derived from A549 cells cultured with ERW (ERWA549 CM) was used to see how ERW influences the tubule formation parameters. The results showed that ERW treatment affected only the total tubule length, decreasing it at a statistically significant level compared to A549 CM treated cells ( $p<0.01$, Fig. 4D: see total tubule length). Although, the total tubule length parameter is commonly used for quantitative analysis of tubule formation, other parameters were also measured. ERW was shown to exert its influence by marginally suppressing the other three parameters, though not to a statistically significant level (Fig. 4D). These results strongly suggested that ERW exerts an inhibitory effect on tumor-induced angiogenesis by way of down-regulating $\mathrm{H}_{2} \mathrm{O}_{2}$ release and VEGF secretion from A549 cells (Fig. 4).

\section{DISCUSSION}

Our findings suggest that ERW reduces $\mathrm{H}_{2} \mathrm{O}_{2}$ induced VEGF expression in a human lung adenocarcinoma cell line, A549. As cancer cells produce ROS, including $\mathrm{H}_{2} \mathrm{O}_{2}$, the release of $\mathrm{H}_{2} \mathrm{O}_{2}$ could be a trigger for the angiogenic process in those cancer cells..$^{9,11,12,14)}$ As well, $\mathrm{H}_{2} \mathrm{O}_{2}$ has also been shown to induce significant VEGF expression in various cell types. $^{33-35)}$ As well, tumor vascularity has been shown to be directly correlated with VEGF production by tumors. ${ }^{36-41)}$ Blockade of tumor secreted VEGF by an anti-VEGF antibody caused significant damage on endothelial cells. ${ }^{42)}$ These results together strongly support the hypothesis that the blockade of $\mathrm{H}_{2} \mathrm{O}_{2}$ release and VEGF secretion from cancer cells has therapeutic value by conferring an antiangiogenic effect. Along this line, antioxidants such as $N$-acetylcystein, vitamin E, catechins, and natural polyphenols from red wine have been evaluated for their efficacy, with positive results. $^{42-47)}$

The signal transduction pathway for VEGF expression is highly divergent and is cell type dependent. Involvement of both phosphatidylinositol 3'-kinase and MAPK/ERK kinase $1 / 2$ in the regulation of VEGF expression is reported in astrocytomas $^{48)}$ and head and neck squamous cell carcinoma, ${ }^{49)}$ while phosphatidylinositol 3'-kinase pathway, but not ERK MAPK regulated VEGF expression is involved in hepatocellular carcinoma. ${ }^{50)}$ As well, p38 MAPK is reported to affect VEGF expression in vascular smooth muscle, ${ }^{43)}$ and breast cancer $^{51)}$ cells, while ERK MAPK does so in fibroblasts, ${ }^{52)}$ and colon carcinoma. ${ }^{53)}$ In the present study, at least ERK was proven to be involved in regulation of VEGF expression in lung adenocarcinoma A549 cells, because only PD98059 blocked VEGF expression in the cells (Fig. 3).

ERK activation is sensitive to redox stress. ${ }^{54-58)}$ Thus, the reduction of redox stress induced in cells or the neutralization of exogenous oxidative stress may block activation of ERK MAPK, which can lead to an alteration of the target gene expression. Epigallocatechin gallate, an antioxidant contained in green tea, inhibited VEGF expression via the suppression of ERK activation in HT29 human colon cancer cells. ${ }^{59)}$ In the current study, ERW inactivated ERK in a timedependent manner, within $4 \mathrm{~h}$, after which ERW showed no further effect on ERK activation. This indicated that the effi- ciency of ERW on ERK activation is only short-term. The inhibition of constitutive VEGF expression in A549 cells can be partially ascribed to the blockade of ERK activation by ERW. Also, we considered possible transcription factor(s) involved in regulating VEGF gene transcription in relation to ROS. Exogenous stimulation of cultured cells by hydrogen peroxide $\left(\mathrm{H}_{2} \mathrm{O}_{2}\right)$ was shown to up-regulate VEGF mRNA in a dose- and time-dependent manner. VEGF mRNA activation was also shown to correlate with an enhanced binding of AP1 and NF- $\kappa$ B. ${ }^{60)} \mathrm{NF}-\kappa \mathrm{B}$ resides in the cytoplasm complexed with the inhibitor protein $\mathrm{I}-\kappa \mathrm{B}$ masking the nuclear localization signal of $\mathrm{NF}-\kappa \mathrm{B}$. NF- $\kappa \mathrm{B}$ is activated by $\mathrm{H}_{2} \mathrm{O}_{2}$ treatment through phosphorylating I- $\kappa \mathrm{B}$ to release NF- $\kappa \mathrm{B}$ for nuclear translocation via the Ras mitogen-activated protein kinase (MAPK) pathway. ${ }^{61)}$ Our present results with specific inhibitors showed that MAPK pathway (p38 and JNK) is not involved (Fig. 3) and thus VEGF mRNA activation by NF$\kappa \mathrm{B}$ is excluded. On the other hand, AP-1 is considered as a redox-sensitive transcription factor ${ }^{62)}$ and thus VEGF mRNA up-regulation by $\mathrm{H}_{2} \mathrm{O}_{2}$ is likely to involve AP-1. Another transcription factor, ETS-1, is up-regulated by $\mathrm{H}_{2} \mathrm{O}_{2}$ via HIF$1 \alpha$ which is stabilized by $\mathrm{H}_{2} \mathrm{O}_{2} \cdot{ }^{63,64)}$ The HIF- $1 \alpha(120 \mathrm{kDa})$ is complexed with HIF- $1 \beta(94 \mathrm{kDa})$ subunit forming functional HIF-1 (hypoxia-inducible factor-1). HIF- $1 \alpha$ is the rate limiting subunit which determines the activity of the HIF-1 complex. ${ }^{65)} \mathrm{HIF}-1 \alpha$ is a short lived protein that is maintained at low and often undetectable levels in normoxia, whereas it is strongly induced in hypoxic cells. $\left.{ }^{66}\right)$ We showed that ERW scavenges endogenous as well as exogenous $\mathrm{H}_{2} \mathrm{O}_{2}$ (Fig. 1) suggesting that HIF-1 regulated ETS-1 involvement is less likely. However, it has been shown that ETS-1 promoter contains several transcription factor binding sites including AP$1^{67)}$ and AP-1 is considered as a redox-sensitive transcription factor. $^{62)}$ Taking all these information into considerations, we deduced AP-1 as the prime candidate for up-regulating VEGF transcription.

Present results uncovered that mRNA levels were dramatically decreased in the cells treated by ERW while secreted protein levels decreased rather slowly. Drastic mRNA decline could be interpreted as that the half-life of VEGF mRNA is $42 \min ^{68)}$ and $43 \pm 6 \min ^{69)}$ under normoxic conditions, while the average half-life of eukaryotic mRNA is $10-12 \mathrm{~h}^{70)}$ Furthermore, the VEGF mRNA contains destabilizing elements in its 5'UTR, coding region and 3'UTR, and three elements act additively to execute rapid degradation under normoxic conditions. $^{71)}$ Our experiments were carried out under normoxic conditions and therefore mRNA is considered to be short lived. In addition, the activities of hydrogen peroxide $\left(\mathrm{H}_{2} \mathrm{O}_{2}\right)$ regulated transcription factors would also be decreased due to lowered $\mathrm{H}_{2} \mathrm{O}_{2}$ levels by scavenging activity of ERW. Considering incubation times $(0.5,4.0,24 \mathrm{~h})$ used and short-half life of VEGF mRNA as well as lowered transcription factor(s) together would explain the drastic decrease of VEGF mRNA levels in the present experimental conditions (Fig. 3A). VEGF protein secreted in the medium is not drastically decreased as mRNA does. Our interpretation is that the levels of VEGF protein assayed are cumulative instead of time point levels. Thus the amount of protein will be accumulated as incubation time is extended up to $24 \mathrm{~h}$. At $24 \mathrm{~h}$ point, control medium contains $1217.94 \pm 61.83 \mathrm{pg} / \mathrm{ml}$ while ERW treated medium contains $1095.53 \pm 21.50 \mathrm{pg} / \mathrm{ml}$ and 
thus ERW treated medium still contains $c a$. $85 \%$ of VEGF protein (Fig. 2B). Then, one would expect that more VEGF protein exist in the conditioned medium, more tubule formation will result. ERW could have reduced $c a$. 15\% VEGF protein compared to control after $24 \mathrm{~h}$ incubation and thus the tubule formation is exerted by $c a$. $85 \%$ VEGF protein. Three criteria show the suppressive tendencies though not statistically significant levels, and showed significant reduction in the total tubule length only (Fig. 4D). Therefore, vascular tubule formation assay is in accordance with the protein levels detected in Fig. 2B (Fig. 4D).

The mechanism underlying how ERW effectively scavenges intracellular $\mathrm{H}_{2} \mathrm{O}_{2}$ remains to be clarified in more detail. ERW contains a high concentration of hydrogen molecule, however, hydrogen molecule is chemically inert at room temperature. In an attempt to overcome this challenging problem, Shirahata et al. proposed an active hydrogen hypothesis of reduced water in which active hydrogen with a high reducing potential was produced in ERW by electrolysis and played a key role in scavenging ROS. ${ }^{24,72)}$ Active hydrogen can be produced from hydrogen molecule by catalysis action of noble metal nanoparticles like platinum nanoparticles. ${ }^{73)}$ Transition metal nanoparticles such as $\mathrm{Pd}, \mathrm{Pt}, \mathrm{Ni}$, and $\mathrm{Cu}$ are produced during the process of electrolysis. ${ }^{74)}$ Platinum nanoparticles have also been demonstrated to adsorb active hydrogen. ${ }^{75)}$ Synthetic platinum nanoparticles were shown to scavenge superoxide radicals. ${ }^{76)}$ There is a possibility that platinum nanoparticles derived from platinum-coated titanium electrode used here during electrolysis and metal nanoparticls of $1-10 \mathrm{~nm}$ size can stably exist in solution for a long time. ${ }^{74)}$ Taken together, here we propose a new hypothesis of reduced water containing metal nanoparticles and hydrogen molecule as follows: (1) Electrolysis produces active hydrogen on the cathodic platinum electrode and hypersaturated hydrogen molecule in ERW. (2) Metal ions in the solution are reduced to metal nanoparticles on the electrode or in hydrogen-rich ERW. (3) Transition metal nanoparticles with low ionic tendencies adsorbed or absorbed active hydrogen can exist stably in ERW but other metal nanoparticles with high ionic tendencies such as $\mathrm{Na}$ and $\mathrm{K}$ disappear in ERW soon. (4) Hydrogen molecule is constantly converted to active hydrogen, which can scavenge ROS, by the catalysis of metal nanoparticles. Some kinds of metal nanoparticles like platinum nanoparticles can also directly scavenge ROS without hydrogen molecule.

On the other hand, Kikuchi et al. hypothesized, in attempting to elucidate the ROS scavenging substance(s) in ERW, that activated molecular hydrogen or hydrogen nanobubbles are responsible for the reducibility of ERW. ${ }^{77-81)}$ Recently, molecular hydrogen was demonstrated to act as a selective antioxidant against cytotoxic oxygen radicals like hydroxyl radical and peroxynitrite. ${ }^{82)}$ Hiraoka et al. reported that ERW and several natural mineral waters also possess reducing activities and hypothesized that it is due to molecular hydrogen and/or reductive vanadium ions. ${ }^{83,84)}$ Hanaoka et al. suggested that the enhancement of superoxide anion radical dismutation activity can be explained by changes in the ionic product of water in ERW. ${ }^{85,86}$ )

Major drawbacks of cancer chemotherapy are the various side-effects of the drugs used and the resistance that can be developing to these drugs. To resolve these problems, an un- derstanding of the biological differences between cancer and normal cells is necessary. It will also be necessary to seek out appropriate therapeutic agents that can block the biological events critical for cancer cells, but not those for normal cells. Cancer cells, as compared to normal ones, are exposed to higher oxidative stresses associated with oncogenic transformation, alterations in metabolic activity, and increased generation of ROS. ERW possesses an advantage over many other antioxidants in that cancer cells with higher oxidative stress are more likely to be affected by ERW, whereas normal cells are not.

Taken together, we demonstrated here for the first time that ERW can suppress angiogenesis induced by A549 cells through down-regulating both $\mathrm{H}_{2} \mathrm{O}_{2}$ release and VEGF expression. Moreover, our study suggested that ERK MAPK plays a critical role in regulating VEGF expression in A549 cells, and that inhibition of VEGF by ERW partially correlated with inactivation of ERK MAPK.

While the present results have pointed out the intracellular target sites regulated by ERW, what component(s) in ERW actually scavenged intracellular $\mathrm{H}_{2} \mathrm{O}_{2}$ remains to be elucidated. Future investigations need to be directed to clarifying the reducing agent(s) in ERW. Also, our future studies could be directed to perform similar experiments under normoxic and hypoxic conditions to learn ERW effects at the gene expression levels which include confirmation of AP-1 involvement.

\section{REFERENCES}

1) Hicklin D. J., Ellis L. M., J. Clin. Oncol., 23, 1011-1027 (2005).

2) Ferrara N., Trends Cardiovasc. Med., 3, 244-250 (1993).

3) Senger D. R., Perruzzi C. A., Feder J., Dvorak H. F., Cancer Res., 46, 5629-5632 (1986)

4) Kunz M., Ibrahim S. M., Mol. Cancer, 2, 23-35 (2003).

5) Berse B., Brown L. F., Van de Water L., Dvorak H. F., Senger D. R., Mol. Biol. Cell, 3, 211-220 (1992).

6) Brown L. F., Berse B., Jackman R. W., Tognazzi K., Guidi A. J., Dvorak H. F., Senger D. R., Connolly J. L., Schnitt S. J., Am. J. Pathol., 143, 1255-1262 (1993).

7) Sato K., Terada K., Sugiyama T., Takahashi S., Saito M., Moriyama M., Kakinuma H., Suzuki Y., Kato M., Kato T., Tohoku J. Exp. Med. 173, 355-360 (1994).

8) Takahashi H., Shibuya M., Clin. Sci., 109, 227-241 (2005).

9) Monte M., Davel L. E., De Lustig S., Eur. J. Cancer, 33, 676-682 (1997).

10) Nilanjana M., Dipak K. D., Free Radic. Biol. Med., 33, 1047-1060 (2002).

11) Stone J. R., Collins T., Endothelium, 9, 231-238 (2002).

12) Qian Y., Luo J., Leonard S. S., Harris G. K., Millecchia L., Flynn D. C., Shi X., J. Biol. Chem., 278, $16189-16197$ (2003).

13) Ushio-Fuaki M., Cardiovasc. Res., 71, 226-235 (2006).

14) Szatrowski T. P., Nathan C. F., Cancer Res., 51, 794-798 (1991).

15) Yoshida T., Maulik N., Engelman R. M., Ho Y.-S., Magnenat J.-L., Rousou J. A., Flack J. E., III, Deaton D., Das D. K., Circulation, 96, 216-220 (1997)

16) Das D. K., Engelman R. M., Rousou J. A., Breyer R. H., Otani H., Lemeshow S., Basic Res. Cardiol., 81, 155-166 (1986).

17) Tosaki A., Droy-Lefaix M. T., Pali T., Das D. K., Free Radic. Biol. Med., 14, 361-370 (1993).

18) Chua C. C., Handy R. C., Chua B. H. L., Free Radic. Biol. Med., 25, $891-897$ (1998)

19) Inoue M., Itoh H., Tanaka T., Chun T.-H., Doi K., Fukunaga Y., Sawada N., Yamshita J., Masatsugu K., Saito T., Sakaguchi S., Sone M., Yamahara K., Yurugi T., Nakao K., Arterioscler Thromb. Vasc. Biol., 21, 560-566 (2001).

20) Nakae H., Inaba H., J. Trauma, 49, 511-514 (2000) 
21) Koseki S., Itoh K., J. Food Prot., 64, 1935-1942 (2001)

22) Vorobjeva N. V., Vorobjeva L. I., Khodjaev E. Y., Artif. Organs, 28, 590-592 (2004)

23) Fujiyama Y., Koyama S., Bamba T., Tashiro H., Ono H., Kitahora T., 7th Functional Water Symposium Abstract, 2000, pp. 74-75.

24) Shirahata S., Kabayama S., Nakano M., Miura T., Kusumoto K., Gotoh, M., Hayashi H., Otsubo K., Morisawa S., Katakura Y., Biochem. Biophys. Res. Commun., 234, 269-274 (1997).

25) Li Y. P., Nishimura T., Teruya K., Tei M., Komatsu T., Hamasaki T., Kashiwagi T., Kabayama S., Shim S.-Y., Katakura Y., Osada K., Kawahara T., Otsubo K., Morisawa S., Ishii Y., Gadek Z., Shirahata S., Cytotechnology, 40, 139-140 (2002).

26) Huang K.-C., Yang C.-C., Lee K.-T., Chien C.-T., Kidney Int., 64, $704-714$ (2003).

27) Huang K.-C., Yang C.-C., Hsu S.-P., Lee K.-T., Kiu H. W., Morisawa S., Otsubo K., Chen C.-T., Kidney Int., 70, 391-398 (2006).

28) Kim M.-J., Kim H. K., Life Sci., 79, 2288-2292 (2006).

29) Ruch W., Cooper P. H., Baggiolini M., J. Immunol. Methods, 63, 347-357 (1983)

30) Tischer E., Mitchell R., Hartman T., Silva M., Gospodarowicz D., Fiddes J. C., Abraham J. A., J. Biol. Chem., 286, 11947-11954 (1991).

31) Ruef J., Hu Z. Y., Yin L.-Y., Wu Y., Hanson S. R., Kelly A. B., Harker L. A., Rao G. N., Runge M. S., Patterson C., Circ. Res., 81, 24-33 (1997).

32) Shono T., Ono M., Izumi H., Jimi S.-I., Matsushima K., Okamoto T., Kohno K., Kuwano M., Mol. Cell Biol., 16, 4231-4239 (1996).

33) Brauchle M., Oliver F. J., Kind P., Werner S., J. Biol. Chem., 271, 21793-21797 (1996).

34) Cho M., Hunt T. K., Hussain M. Z., Am. J. Physiol. Heart Circ. Physiol., 280, H2357-H2363 (2001).

35) Zhu J.-W., Yu B.-M., Ji Y.-B., Zheng M.-H., Li D.-H., World J. Gastroenterol., 8, 153-157 (2002).

36) Berkman R. A., Merrill M. J., Reinhold W. C., Monacci W. T., Saxena A., Clark W. C., Robertson J. T., Ali I. U., Oldfield E. H., J. Clin. Invest., 91, 153-159 (1993)

37) Wizigmann-Voss S., Breier G., Risau W., Cancer Res., 55, 1358 1364 (1994).

38) Guidi A. J., Abu-Jawdeh G., Berse B., Jackman R. W., Tognazzi K., Dvorak H. F., Brown L. F., J. Natl. Cancer Inst., 87, 12137-12145 (1995).

39) Mattern J., Koomagi R., Volm M., Br. J. Cancer, 73, 931 -934 (1996).

40) Suzuki K., Hayashi N., Miyamoto Y., Yamamoto M., Ohkawa K., Ito Y., Sasaki Y., Yamaguchi Y., Nakase H., Noda K., Enomoto N., Arai K., Yamada Y., Yoshihara H., Tujimura T., Kawano K., Yoshikawa K., Kamada T., Cancer Res., 56, 3004-3009 (1996).

41) Balsari A., Maier J. A., Colnaghi M. I., Menard S., Lab. Invest., 79, 897-902 (1999).

42) Malafa M. P., Fokum F. D., Smith L., Louis A., Ann. Surg. Oncol., 9 1023-1032 (2002).

43) Oak M.-H., Chataigneau M., Keravis T., Chataigneau T., Beretz, A., Andriantsitohaina R., Stoclet J.-C., Chang S.-J., Schini-Kerth V. B., Arterioscler. Thromb. Vasc. Biol., 23, 1001-1007 (2003).

44) Agarwal A., Munoz-Najar U., Klueh U., Shih S.-C., Claffey K. P., Am. J. Pathol., 164, 1683-1696 (2004).

45) Castilla M. A., Neria F., Renedo G., Pereira D. S., Gonzalez-Pacheco F. R., Jimenez S., Tramon P., Deudero J. J. P., Arroyo M. V. A., Yaguee S., Caramelo C., Am. J. Physiol. Cell. Physiol., 286, C1170-C1176 (2004).

46) Tang F.-Y., Chiang E.-P. I., Shih C.-J., J. Nutr. Biochem., 18, 391-399 (2007).

47) Sadowska A. M., Manuel-y-Keenoy B., De Backer W. A., Pulm. Pharmacol. Ther, 20, 9-22 (2007).

48) Woods S. A., McGlade C. J., Guha A., Neuro-Oncology, 4, 242-252 (2002).

49) Dong G., Chen Z., Li Z. Y., Yeh N. T., Bancroft C. C., Van Waes C., Cancer Res., 61, 5911-5918 (2001).

50) Huang G. W., Yang L. Y., Lu W. Q., World J. Gastroenterol., 10, 809812 (2004).

51) Xiong S., Grijalva R., Zhang L., Nguyen N. T., Pisters P. W., Pollock R. E., Yu D., Cancer Res., 61, 1727-1732 (2001).

52) Milanini J., Vinals F., Pouyssegur J., Pages G., J. Biol. Chem., 273 $18165-18172$ (1998).
53) Jung Y. D., Nakano K., Liu W., Gallick G. E., Ellis L. M., Cancer Res., 59, 4804-4807 (1999).

54) Guyton K. Z., Liu Y., Gorospe M., Xu Q., Holbrook N. J., J. Biol. Chem., 271, 4138-4142 (1996).

55) Aikawa R., Komuro I., Yamazaki T., Zou Y., Kudoh S., Tanaka M., Shiojima I., Hiroi Y., Yazaki Y., J. Clin. Invest., 100, 1813-1821 (1997).

56) Abe M. K., Kartha S., Karpova A. Y., Li. J., Liu P. T., Kuo W. L., Hershenson M. B., Am. J. Respir. Cell. Mol. Biol., 18, 562-569 (1998).

57) Wang X., Martindale J. L., Liu Y., Holbrook N. J., Biochem. J., 333 291-300 (1998)

58) Gaitanaki C., Konstantina S., Chrysa S., Beis I., J. Exp. Biol., 206, $2759-2769$ (2003).

59) Jung Y. D., Kim M. S., Shin B. A., Chay K. O., Ahn B. W., Liu W., Bucana C. D., Gallick G. E., Ellis L. M., Br. J. Cancer, 84, 844-850 (2001).

60) Chua C. C., Handy R. C., Chua B. H. L., Free Radic. Biol. Med., 25 891-897 (1998)

61) Eyries M., Collins T., Khachigian L. M., Endothelium, 11, 133-139 (2004).

62) Ordway J. M., Eberhart D., Curraqn T., Mol. Cell. Biol., 23, 42574266 (2003).

63) Wilson L. A., Gemin A., Espiritu R., Singh G., FASEB J., express article 10.1096/fj.05-4401fje (2005).

64) Oikawa M., Abe M., Kurosawa H., Hida W., Biochem. Biophys. Res. Commun., 289, 39-43 (2001).

65) Huang L. E., Arany Z., Livingston D. M., Bunn H. F., J. Biol. Chem., 271, 32253-32259 (1996).

66) Berra E., Pages G., Pouyssegur J., Cancer Metastasis Rev., 19, 139 145 (2000).

67) Chen J. H., Wright C. D., Oncogene, 8, 3375-3383 (1993).

68) Liu L. X., Lu H., Luo Y., Date T., Belanger A. J., Vincent K. A., Akita G. Y., Goldberg M., Cheng S. H., Gregory R. J., Jiang C., Biochem. Biophys. Res. Commun., 291, 908-914 (2002).

69) Levy A. P., Levy N. S., Goldberg M. A., J. Biol. Chem., 271, 27462753 (1996).

70) Yoo P. S., Mulkeen A. L., Cha C. H., World J. Gastroenterol., 12 4937-4942 (2006)

71) Dibbens J. A., Miller D. L., Damert A., Risau W., Vadas M. A., Goodall G. J., Mol. Biol. Cell., 10, 907-919 (1999).

72) Shirahata S., "Animal Cell Technology: Basic \& Applied Aspects," Proceedings of the 13th JAACT Meeting, 16-21 November, 2000, ed. by Shirahata S., Teruya K., Katakura Y., Kluwer, Fukuoka-Karatsu, Japan, 2002, pp. 25-30.

73) Minaev B., Ågren H., J. Mol. Catal. A, 149, 179-195 (1999).

74) Roucoux A., Schulz J., Patin H., Chem. Rev., 102, 3757-3778 (2002).

75) Isobe Y., Yamauchi M., Ikeda R., Kitagawa H., Synthetic Metals, 135-136, 757-758 (2003).

76) Hamasaki T., Kashiwagi T., Aramaki S., Imada T., Komatsu T., Li Y., Teruya K., Katakura Y., Kabayama S., Otubo K., Morisawa S., Shirahata S., "Animal Cell Technology Meets Genomics," Proceedings of the 18th ESACT Meeting, 11-14 May, 2003, ed. by Godia F., Fussenegger M., Springer, Granada, Spain, 2005, pp. 249-251.

77) Kikuchi K., Takeda H., Rabolt B., Okaya T., Ogumi Z., Saihara Y., Noguchi H., J. Electroanal. Chem., 506, 22-27 (2001).

78) Kikuchi K., Takeda H., Rabolt B., Okaya T., Ogumi Z., Saihara Y., Noguchi H., J. Appl. Electrochem., 31, 1301-1306 (2001).

79) Kikuchi K., Tanaka Y., Saihara Y., Maeda M., Kawamura M., Ogumi Z., J. Colloid Interface Sci., 298, $914-919$ (2006).

80) Kikuchi K., Tanaka Y., Saihara Y., Ogumi Z., Electrochim. Acta, 52 904-913 (2006)

81) Kikuchi K., Nagata S., Tanaka Y., Saihara Y., Ogumi Z., J. Electroanal. Chem., 600, 303-310 (2007).

82) Ohsawa I., Ishikawa M., Takahashi K., Watanabe M., Nishimaki K. Yamagata K., Katsura K.-I., Katayama Y., Asoh S., Ohta S., Nat. Med., 13, 688-694 (2007).

83) Hiraoka A., Takemoto M., Suzuki T., Shinohara A., Chiba M., Shirao M., Yoshimura Y., J. Health Sci., 50, 456-465 (2004).

84) Hiraoka A., Sasaki S., Yamada T., Shinohara A., Chiba M., J. Health Sci., 52, 817-820 (2006).

85) Hanaoka K., J. Appl. Electrochem., 31, 1307-1313 (2001).

86) Hanaoka K., Sun D., Lawrence R., Kamitani Y., Fernandes G., Biophys. Chem., 107, 71-82 (2004). 